\title{
Research Paper: Gene Expression Survey of Serotonin Receptors (5HTR2A and 5HTR3A) and Monoamine Oxidases Enzyme After Treatment With Methadone in Addicted Individuals
}

Mahmood Khodadoost ${ }^{1}$, Mohadeseh Khoshandam ${ }^{2}$, Seyed Davood Mirtorabi ${ }^{3}$, Mohammad Reza Ghadirzadeh ${ }^{4}$, Ghasem Ahangari ${ }^{*}{ }^{*}$

1. Traditional Medicine and Materia Medica Research Center, Shahid Beheshti University of Medical Sciences, Tehran, Iran.

2. Department of Medical Genetics, Faculty of Medical Biotechnology, National Institute of Genetic Engineering and Biotechnology, Tehran, Iran.

3. Department of Neurosciences and Addiction Studies, School of Advanced Technologies in Medicine, Tehran University of Medical Sciences, Tehran, Iran

4. Department of Addiction, Legal Medicine Research Center, Legal Medicine Organization, Tehran, Iran.

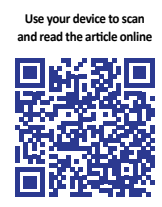

Crtation: Khodadoost M, Khoshandam M, Mirtorabi SD, Ghadirzadeh MR, Ahangari G. Gene Expression Survey of Serotonin Receptors (5HTR2A and 5HTR3A) and Monoamine Oxidases Enzyme After Treatment With Methadone in Addicted Individuals. International Journal of Medical Toxicology and Forensic Medicine. 2019; 9(3):125-132. https://doi.org/10.32598/jimtfm.v9i3.25480

https://doi.org/10.32598/ijmtfm.v9i3.25480

\section{(A) 03}

Article info:

Received: 01 Feb 2019

First Revision: 24 Feb 2019

Accepted: 29 May 2019

Published: 01 Jul 2019

Keywords:

Addiction, Heroin, Types of serotonin, Enzyme MAOA, Methadone, MMT

\begin{abstract}
A B STRACT
Background: Addiction disrupts the nervous system of the reward system, stimulus, and memory in the brain. The disruption of these systems in the brain causes biological, physiological, social, and psychological complications. Addiction is considered a psychological, social, and economic disorder in terms of medicine, psychology, and sociology, as well as philosophy, law, ethics, and religion. The most important place of narcotic effect is the brain, and receptors affect these substances. Dopamine and serotonin receptors are among the most important receptors, in which drugs affect them. Methadone is also an opiate drug that is even more addictive than morphine and heroin and is often used as a preservative to control heroin and narcotic addiction.
\end{abstract}

Methods: In this study, 3 genes of 5-Hydroxytryptamine Receptor 2 A (5HT2Ra), 5-Hydroxytryptamine Receptor 3 A (5HT3Ra), and Monoamine Oxidases A (MAOA), which play an important role in serotonin function, were examined in Peripheral Blood Mononuclear Cells (PBMCs) of heroin addicts, who had been quitting addiction with methadone for 3 months. Therefore, peripheral blood PBMCs were isolated. cDNA was synthesized from mRNA; then, the expression of the gene was measured by real-time Polymerase Chain Reaction (PCR).

Results: The expression of MAOA gene in the PBMCs of the addicted patients with methadone was significantly reduced compared to the control group, while the expression of 5HT2Ra and 5HT3Ra genes showed no change in the two groups.

Conclusion: These results suggest that Methadone Maintenance Treatment (MMT) may be moderated by $5 \mathrm{HT} 2 \mathrm{Ra}$ and $5 \mathrm{HT} 3 \mathrm{Ra}$ serotonin receptors and returned to their previous efficacy, but MAOA was significantly reduced.

* Corresponding Author:

Ghasem Ahangari, PhD.

Address: Department of Medical Genetics, Faculty of Medical Biotechnology, National Institute of Genetic Engineering and Biotechnology, Tehran, Iran. Tel: +98 (912) 8103450

E-mail: ghah@nigeb.ac.ir 


\section{Introduction}

A

$\mathrm{s}$ a mental disease, addiction causes changes in the brain, resulting in drug addiction [1]. Genetic factors and psychiatric disorders can greatly contribute to drug addiction [2]. For a long time, genetic factors associated with environmental factors (for example, mental disorders) have played an important role in the vulnerability of addiction [3]. According to a report in February 2017, the total number of addicts was more than 2.5 million in Iran. Around (17\%) of people tend to use drugs according to the United Nations Office on Drugs and Crime (UNODC) in 2014. Iran has a significant number of drug users; so, the drug use rate is a particular concern for our country.

As addiction develops, it changes the nervous system that may occur in the key circuits of the brain and help develop and maintain addiction. While dopaminergic and glutamatergic circuits play a decisive role in addiction, important advances have been made in identifying serotonergic mechanisms and their addictive processes in recent years. In addition, the increasing evidence states that the impairment of serotonin regulation may cause drug dependence $[4,5]$.

Also known as 5-Hydroxytryptamine (5-HT), serotonin can be found in almost every region of the central nervous system [5]. It affects the immune system, the digestive tract, neurology, para-quinone, and endocrine system. Serotonin is first metabolized to 5-hydroxyindole acetaldehyde by monoamine oxidase; it is, then, catalyzed by aldehyde dehydrogenase to form 5-hydroxyindole acetic acid [6-9].

A number of studies have shown that a disorder in the serotonin 5-HT system can lead to behavioral disorders, psychiatry, and substance abuse disorders [10]. Addiction also disrupts the serotonergic system [11]; 5 HT receptors are present on nerve cell membranes and other types of cells in organisms, thereby mediating as serotonin-like ligand ion channel for the effects of serotonin and a wide range of hallucinogenic and psychotropic drugs $[12,13]$. The increased synaptic effects of 5 HT with amplified responses to 5HT3 may upsurge the transfer of dopamine to the reward path, which predicts an increased risk of addiction [14].

Because of the crucial role that Monoamine Oxidases (MAOs) play in the neutralization of neurotransmitters, it (dysfunction or excessive activity) is thought to be related to some psychiatric and neurological disorders.
MAO inhibitors are one of the most important medications prescribed for the treatment of these disorders [15]. Methadone is an industrial drug that is often used as a preservative to control heroin and narcotic addiction [16]. It is also an analgesic drug that has a long half-life and, therefore, can accumulate and has an analgesic effect 8 to 12 hours after dosing [17]. Methadone is slowly excreted; so, it can be taken only once a day [17]. Opioid addiction is a major public health issue worldwide. Methadone Maintenance Treatment (MMT) is used to detoxify the users of illicit drugs [18].

The aim of this study was to measure the relative expression of the 5-HT2A, 5-HT3A, and MAOA receptor at mRNA level in PBMCs of the patients (quitting heroin) with methadone maintenance medication.

\section{Materials and Methods}

\section{Sampling}

The volunteers were selected from the addicts after reviewing and having the desired conditions. A total of 40 addicted individuals, who had more than 6-month heroin addiction and were aged between 23 and 55 years, were selected. The Peripheral Blood Mononuclear Cells (PBMCs) of heroin addicts, who had been quitting addiction with methadone hydrochloride oral solution ( $250 \mathrm{mg}$, Exir, Iran) once a day for 3 months were examined. After 3-month treatment with methadone hydrochloride once a day, we collected samples as below. Normal individuals from people, who lived without drug use, were selected from 40 healthy individuals aged 23 to 55 years old; they were not depended to any drug and addiction (Table 1). This project was confirmed by the Ethics Committee of Legal Medicine Research Center, Legal Medicine Organization, Tehran, Iran based on Helsinki declaration ethics. The participants signed the consent form.

\section{PBMC separation}

For syringe sampling, $5 \mathrm{~mL}$ of venous blood was taken from healthy and addicted individuals. Blood was discharged into a sterile tube containing EthylenediamineTetraacetic Acid (EDTA). Subsequently, the Falcon tube was placed on a cool flask to transfer to the research institute. PBMCs were separated by Ficoll-Hypaque density gradient centrifugation (Pharmacia, Uppsala, Sweden). The lymphocyte layer was collected and washed 3 times in Phosphate-Buffered Saline (PBS). 


\section{RNA extraction and cDNA synthesis}

The total mRNA from the lymphocytes was extracted by RNA mini kit (Roach, Germany), and the amount and purity of the RNA were measured by spectrophotometry. For cDNA synthesis, the cDNA synthesis kit (Fermentase, Germany) was used. Also, cDNA synthesis, the basis of the production protocols, was performed. Finally, cDNA samples were stored at $-70^{\circ} \mathrm{C}$ and the reference cDNA was followed-up.

\section{Primers, PCR, and Real-Time PCR Analyzes}

Primers for 5HT2Ra, 5HT3Ra, MAOA, and the housekeeping gene ( $\beta$-actin) were designed, using Primer Express software to exclude the amplification of genomic DNA and pseudogenes and to confirm the validity of these primers by blasting these primers ${ }^{1}$. Table 2 presented primer sequences. A 75ng sample of cDNA was used for PCR amplification in a final volume of $25 \mu \mathrm{L}$ with 1 unit of Taq DNA polymerase.

We used Techne Flexigene PCR cycles, Minneapolis, $\mathrm{MN}$, and USA to amplify target and control genes. Betaactin, 5HT2Ra, 5HT3Ra, and MAOA transcripts were quantified in samples, using real-time PCR (Rotor gene, Corbett, Germany) and LightCycler ${ }^{\circledR}$ FastStart DNA MasterPLUS SYBR Green I kit (Roche, Germany) with specific primers (Table 2).

\section{Statistical analysis}

Real-time PCR data were inserted to LinReg software in order to calculate mean and individual efficiency and Cycle Threshold $(\mathrm{Ct})$ of each sample. The gene expression ratios and P-value analysis of HTR2a, 5HTR3a, and MAOA were performed by REST 2009 (Relative Expression Software Tool 2009) program. P-values less than 0.05 were considered significant.

1. http://www.ncbi.nlm.ih.gov/tools/primer-blast/
The efficiency of each reaction was determined precisely by LinRegPCR software. Real-time PCR data were analyzed by Rest 2009 software. Also, the significant value was less than $0.05(\mathrm{P}<0.05)$.

\section{Results}

As shown in Table 1, the age range of 40 cases (heroin addicts) and 40 patients in the control group was 23 to 55 years. Men formed the case group; $(70 \%)$ of the patients had a family history of addiction.

We evaluated the differences between the expressions of two serotonin receptor subtypes (5HTR3A and 5HTR2A) and MAOA genes in addicted and healthy individuals' $\mathrm{PBMC}$ by a highly sensitive method of real-time PCR. The amplicon size was confirmed, using gel electrophoresis and sequencing. The sizes of the target gene amp icon were 225bp, $180 \mathrm{bp}, 466 \mathrm{bp}$, and $231 \mathrm{bp}$ for beta-actin, 5HTR2A, 5HTR3A, and MAOA, respectively.

The results of real-time PCR showed that all 3 target genes and housekeeping gene were expressed in PBMC of addicted and healthy individuals; the expression of MAOA gene in PBMCs of addicted individuals treated with methadone was significantly reduced compared with the control group. While the expression of 5HT2Ra and 5 HT3Ra genes showed no significant change in no group (Table 3 ).

Figure 1 showed the comparison of expression of 5HT2Ra, 5HT3Ra, and MAOA in the addicted individuals, who were quitting heroin under the treatment of methadone syrup compared with healthy individuals.

\section{Discussion}

The addiction is a major, chronic, and neurological disease that develops because of genetic, physiological,

Table 1. Characteristics of addicted and healthy individuals $(n=40)$

\begin{tabular}{ccc}
\hline Parameter & Addicted Individuals & Healthy Individuals \\
\hline Median age $(\mathrm{y})$ & $23-55$ & 25 male/ 15 female \\
Sex (male/female) & 40 male & Heroin \\
Drug addiction & Methadone syrup & - \\
The drug is consumed & 3 months \\
\hline Duration of treatment with methadone syrup & & International Journal of \\
\hline
\end{tabular}


Table 2. Primers used in real-time PCR

\begin{tabular}{|c|c|c|c|c|}
\hline Locus & & Primers & Accession Number & Amplicon Size \\
\hline \multirow{3}{*}{ Beta actin } & $\mathrm{F}$ & 5'- AGACGCAGGATGGCATGGG-3' & \multirow{3}{*}{ NM_001101.3 } & \multirow{3}{*}{$161 \mathrm{bp}$} \\
\hline & & & & \\
\hline & $\mathrm{R}$ & 5'- GAGACCTTCAACACCCCAGCC-3' & & \\
\hline \multirow{3}{*}{ 5HTR2A } & $\mathrm{F}$ & 5'- CCATCCAGAATCCCATCCACC-3' & \multirow{3}{*}{ NM_001165947.2 } & \multirow{3}{*}{$180 \mathrm{bp}$} \\
\hline & & & & \\
\hline & $\mathrm{R}$ & 5'- GGACAAAGTTATCATCGGCGAG-3 & & \\
\hline \multirow{3}{*}{ 5HTR3A } & $\mathrm{F}$ & 5'- GGTACCGGCAGTACTGGA-3' & \multirow{3}{*}{ NM_001161772.2 } & \multirow{3}{*}{466 bp } \\
\hline & & & & \\
\hline & $\mathrm{R}$ & 5'- CGGCGGATGACCACATAG-3' & & \\
\hline \multirow{3}{*}{ MAOA } & $\mathrm{F}$ & 5'- GCTGGACAAAGACTGCTAGGCGG -3' & \multirow{3}{*}{ NM_000240.2 } & \multirow{3}{*}{225 bp } \\
\hline & & & & \\
\hline & $\mathrm{R}$ & 5'- GCTTCACTTGGTCTCCGAGGAGGT -3' & & \\
\hline
\end{tabular}

Table 3. Gene expression analysis of target genes (5HT2AR, 5HT3AR, MAOA) in PBMC

\begin{tabular}{cccc}
\hline Gene & $\mathbf{P}$ & Expression & Changes \\
\hline 5HTR2A & 0.92 & 1.02 & NORMAL \\
\hline 5HTR3A & 0.84 & 1.04 & NORMAL \\
MAOA & 0.001 & 0.12 & DOWN \\
\hline & & & $\begin{array}{c}\text { International Journal of } \\
\text { Medical Toxicology \& Forensic Medicine }\end{array}$
\end{tabular}

and social factors; the characteristic of the disease is a disturbance in the control of the practice or the feeling of being compelled to perform a certain act about dangerous consequences [19]. Addiction is a complex but curable disease that affects brain function and behavior [2]. Additionally, addiction is a disorder in the brain reward system that occurs through transcriptional and epigenetic mechanisms, and over time, it is exposed to a high level of the addictive stimulus [20].

This anticipated the high rates of recurrence of addicts after detoxification as a result of the use of heroin and permanent impairment in the nervous system. Methadone compensates for this defect at the appropriate daily dose. Some patients with a long history of heroin use and after quitting heroin, while getting treatment, discontinue. A major challenge for future research is identifying specific defects in the receiver's function and repair. Meanwhile, quitting methadone addiction is a safe and effective way to normalize the function of addicts [21].

Many clinical studies have shown that methadone is used to reduce the side effects of narcotics, such as heroin, and drug dependence; it prevents drug use by blocking all opioid receptors and reducing drug addic- tion. Methadone was also used as a drug for the treatment of addiction, and when properly used, people unable to engage in social activities can do this because they have been detoxified from heroin [21]. It is also important to maintain methadone with high doses for heroin inhibition [22]. One of the effective therapists at the center of addiction treatment is the use of methadone syrup as a supportive agent for drug discontinuation, especially heroin [22].

In particular, methadone works by "occupying" brainreceptor sites under the influence of heroin and other drugs; as e result, it stops the inevitable and sedative effects of the drug and also prevents drug-induced narcotics [16] and significantly higher rates of levodil acetate, buprenorphine, and methadone in low doses of addictive symptoms decrease [17]. Thus, methadone stops the inevitable and sedative effects of narcotics while preventing drug trafficking.

It also significantly reduces the use of illegal drugs compared to high doses of levodil acetate, buprenorphine, methadone, and low doses of methadone [17]. So, we used it to help the addicted individuals as an auxiliary drug; it works as the "occupation" of brain-receptor sites 


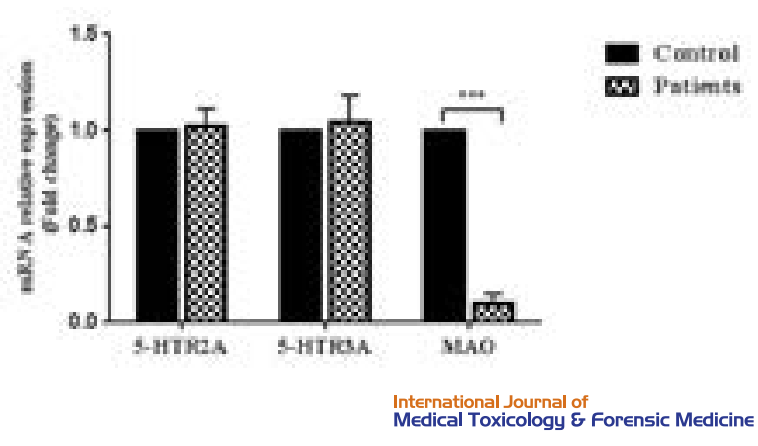

Figure 1. Expression of 5HTR2A, 5HTR3A, and MAOA in addicted and healthy individuals

under the influence of heroin and other drugs. Hence, we sampled the addiction to heroin and chose methadone as an adjunct drug for patients, who wanted to quit the addiction. The main goals of this research were to prove these hypotheses; "Will the serotonin receptors (5HT2Ra and 5HT3Ra) and MAO enzyme in addicted people quitting heroin with their methadone syrup return to their previous performance?" Neuroscience, immunologic, and drug studies emphasize the role of 5-HT2A and 5-HT3A serotonin receptors in the pathophysiology of addiction.

Most of the studies conducted on these receptors and enzymes are related to neurological diseases, such as alcoholism, mania, depression, schizophrenia, and behavioral disorders, because these receptors play a role in regulating the charge of cell membranes; hence, they are involved in mental states, as well as molecular studies in this regard $[23,24]$. A study has shown that the long-term use of drugs causes changes in the delivery of cellular transducers and brain receptors (systems that are responsible for sending messages in the brain) [25]. The study also states that the drug increases the activity of at least 3 neurotransmitters and their receptors, including serotonin, dopamine, and norepinephrine, which affect the brain [26-28].

National Institute on Drug Abuse (NIDA) states that drugs increase the level of neurotransmitters and their receptors in the synapse (by increasing their release from the nerve endings and or inhibiting their recruitment) [28-30]. MDMA releases more serotonin and norepinephrine than dopamine. Serotonin is a neurotransmitter that plays an important role in regulating mood, sleep, pain, appetite, and other behaviors. The excessive release of serotonin by MDMA is likely to increase the morale of individuals. [31, 32]. By releasing a large amount of serotonin, the brain significantly destroys this neu- rotransmitter, resulting in negative psychosocial effects that may remain several days after ingestion $[33,34]$.

Therefore, we presented the expression of 5HTR2a serotonin receptors that are receptors of $\mathrm{G}$ protein and 5 HTR3a, which is the only serotonin receptor-dependent on the ion channel, as well as MAOA, a serotonin-inhibiting enzyme located in the mitochondrial membrane, which is studied in methadone-treated addicted patients.

A study has also reported that addictive substances, including heroin and amphetamine derivatives (MDMA), are associated with serotonergic toxicity; this includes decreasing the level of serotonin receptors, reducing the activity of synthetic erode, and the serotonergic activity of serotonergic fibers in animal models [35, 36]. Alternative amphetamines cause serotonin to pass the neurons $[36,37]$; so, it is unclear whether serotonergic fibers actually disappear after taking narcotic drugs [25, 38].

Based on our finding, the expression of 5HT2Ra and 5HT3Ra receptors in heroin-addicted patients, who have quitted the methadone supplementation drug, was normal and showed no significant decrease or increase. These results indicate that 5HT2Ra and 5HT3Ra receptors in serotonergic systems can be restored. In line with our hypothesis, NIDA recommends that an addict should remain on the treatment for at least 90 days, if necessary, in a treatment program. It is time for the brain to provide new neurotransmitters, new habits, and brain chemistry [25].

In 2010, the Department of Psychology and the Drug Abuse Research Center at Temple University studied restoring brain function after the end of various drugs recreations, including hemp, MDMA, and methamphetamine. Addicts that refused to be addicted for 6 months were poorer in motor and verbal skills, as well as psychological duties than in similar peers, who had never used them. After 12 and 17 months, their ability to perform many tasks with motor and verbal skills improved by the lack of the consumption of users [25].

Brain image studies also show that the brain neurobiological disorders as a result of the use of addictive drugs can remain for a long time, but the brain of methadoneaddicted patients' brain to the brain of the control group who never consumed the drug is more similar than that of the addicted patients [38]. It has also been proven that narcotics such as heroin inhibit the activity of the MAOA enzyme; they also increase the activity of monoamine promoters, such as dopamine and serotonin, and are responsible for the strengthening and developing 
drug addiction [39]. They are opiate, Methadone has also been shown to be a serotonin-reuptake inhibitor [40, 41].

\section{Conclusion}

The results of this study suggest that MMT may be moderated by 5 HT2Ra and 5 HT3Ra serotonin receptors and returned to their previous efficacy, but not MAOA enzymes. The result, which gives a glimpse of this research, is the fact that methadone plays a very important role in modulating the serotonin system.

\section{Ethical Considerations}

\section{Compliance with ethical guidelines}

There was no ethical considerations to be considered in this research.

\section{Funding}

This project was supported by Grant: 601 from the Legal Medicine Research Center, Legal Medicine Organization, Tehran, and National Institute for Genetic Engineering and Biotechnology.

\section{Author's contributions}

All authors contributed in preparing this article

\section{Conflict of interest}

The authors declared no conflict of interest.

\section{References}

[1] Volkow ND, Morales M. The brain on drugs: From reward to addiction. Journal of Cell. 2015; 162(4):712-25. [DOI:10.1016/j. cell.2015.07.046] [PMID]

[2] Nestler EJ. Cellular basis of memory for addiction. Dialogues in Clinical Neuroscience. 2013; 15(4):431-43. [PMID] [PMCID]

[3] Vassoler FM, Sadri-Vakili G. Mechanisms of transgenerational inheritance of addictive-like behaviors. Neuroscience. 2014; 264:198-206. [DOI:10.1016/j.neuroscience.2013.07.064] [PMID] [PMCID]

[4] Kirby LG, Zeeb FD, Winstanley CA. Contributions of serotonin in addiction vulnerability. Neuropharmacology. 2011; 61(3):421-32. [DOI:10.1016/j.neuropharm.2011.03.022] [PMID] [PMCID]

[5] Dankoski EC, Wightman RM. Mark Wightman. Monitoring serotonin signaling on a sub second time scale. Frontiers in Integrative Neuroscience. 2013; 7:44. [DOI:10.3389/fnint.2013.00044] [PMID] [PMCID]

[6] Idzko M, Panther E, Stratz C, Müller T, Bayer H, Zissel G, et al. The serotoninergic receptors of human dendritic cells: Identification and coupling to cytokine release. Journal of Immunology (Baltimore). 2004; 172(10):6011-9. [DOI:10.4049/ jimmunol.172.10.6011] [PMID]

[7] Sikander A, Rana SV, Prasad KK. Role of serotonin in gastrointestinal motility and irritable bowel syndrome. Clinica Chimica Acta; International Journal of Clinical Chemistry. 2009; 403 (1-2):47-55. [DOI:10.1016/j.cca.2009.01.028] [PMID]

[8] Murphy DL, Andrews AM, Wichems CH, Li Q, Tohda M, Greenberg B. Brain serotonin neurotransmission: An overview and update with an emphasis on serotonin subsystem heterogeneity, multiple receptors, interactions with other neurotransmitter systems, and consequent implications for understanding the actions of serotonergic drugs. The Journal of Clinical Psychiatry. 1998; 59(suppl. 15):4-12. [PMID]

[9] Martin AM, Young RL, Leong L, Rogers GB, Spencer NJ, Jessup CF, et al. The diverse metabolic roles of peripheral serotonin. Endocrinology. 2017; 158(5):1049-63. [DOI:10.1210/ en.2016-1839] [PMID]

[10] Caspi A, Sugden K, Moffitt TE, Taylor A, Craig IW, Harrington $\mathrm{H}$, et al. Influence of life stress on depression: Moderation by a polymorphism in the 5-HTT gene. Science (New York). 2003; 301(5631):386-9. [DOI:10.1126/science.1083968] [PMID]

[11] Wang RY, Chen HJ, Huang CL, Wang JY, Lee TE, Lee HY, et al. Impacts of GRIN3A, GRM6 and TPH2 genetic polymorphisms on quality of life in methadone maintenance therapy population. PLoS One. 2018; 13(7):e0201408. [DOI:10.1371/ journal.pone.0201408] [PMID] [PMCID]

[12] Arreola R, Becerril-Villanueva E, Cruz-Fuentes C, VelascoVelázquez MA, Garcés-Alvarez ME, Hurtado-Alvarado G, et al. Immunomodulatory effects mediated by serotonin. Journal of Immunology Research.354957. [DOI:10.1155/2015/354957] [PMID] [PMCID]

[13] Hannon J, Hoyer D. Molecular biology of 5-HT receptors. Behavioural Brain Research. 2008; 195(1):198-213. [DOI:10.1016/j.bbr.2008.03.020] [PMID]

[14] Johnson RE, Chutuape MA, Strain EC, Walsh SL, Stitzer ML, Bigelow GE. A comparison of levomethadyl acetate, buprenorphine, and methadone for opioid dependence. The New England Journal of Medicine. 2000; 343(18):1290-7. [DOI:10.1056/NEJM200011023431802] [PMID]

[15] Oreland L. Platelet monoamine oxidase, personality and alcoholism: The rise, fall and resurrection. Neurotoxicology. 2004; 25(1-2):79-89. [DOI:10.1016/S0161-813X(03)00115-3]

[16] Sunilkumar MM, Lockman K. Practical pharmacology of methadone: A long-acting opioid. Indian Journal of Palliative Care. 24(suppl. 1):S10-14. [DOI:10.4103/IJPC.IJPC_180_17] [PMID] [PMCID]

[17] Weber L. How does methadone work? [Internet]. 2012 [Updated 2018 October 13]. Available from: https://prescription-drug.addictionblog.org/how-does-methadone-work/ 
[18] Kreek MJ. Methadone-related opioid agonist pharmacotherapy for heroin addiction. History, recent molecular and neurochemical research and future in mainstream medicine. Annals of the New York Academy of Sciences. 2000; 909:186216. [DOI:10.1111/j.1749-6632.2000.tb06683.x] [PMID]

[19] Gould TJ. Addiction and cognition addict. Addiction Science \& Clinical Practice. 2010; 5(2):4-14. [PMID] [PMCID]

[20] Ruffle JK. Molecular neurobiology of addiction: What's all the $(\Delta)$ FosB about? The American Journal of Drug and Alcohol Abuse. 2014; 40(6):428-37. [DOI:10.3109/00952990.2014.9 33840] [PMID]

[21] Dole VP. Implications of methadone maintenance for theories of narcotic addiction. The Journal of the American Medical Association. 1988; 260(20):3025-9. [DOI:10.1001/ jama.260.20.3025] [PMID]

[22] Hartel DM, Schoenbaum EE, Selwyn PA, Kline J, Davenny $\mathrm{K}$, Klein RS, et al. Heroin use during methadone maintenance treatment: The importance of methadone dose and cocaine use. American Journal of Public Health. 1995; 85(1):83-8 [DOI:10.2105/AJPH.85.1.83] [PMID] [PMCID]

[23] Mück-Seler D, Pivac N. Serotonin. Periodicum Biologorum Universal Decimal Classification. 113(1):29-41.

[24] Hapfelmeier G, Tredt C, Haseneder W, B. Eisensamer, Rupprecht R, Rammes G. Co-expression of the 5-HT3B serotonin receptor subunit alters the biophysics of the 5 -ht 3 receptor. Biophysical Journal. 84(3):1720-33. [DOI:10.1016/S00063495(03)74980-7]

[25] Buddy T. Brain Recovery After Stopping Methamphetamine [Internet]. 2019 [Updated 2019 July 25]. Available from: https:/ / www.verywellmind.com/brain-recovery-possiblefor-meth-users-67583

[26] Gough B, Ali SF, Slikker WJ, Holson RR. Acute effects of 3,4-methylenedioxymethamphetamine (MDMA) on monoamines in rat caudate. Pharmacology Biochemistry and Behavior. 1991; 39(3):619-23. [DOI:10.1016/0091-3057(91)90137Q]

[27] Schmidt CJ, Levin JA, Lovenberg W. In vitro and in vivo neurochemical effects of methylenedioxymethamphetamine on striatal monoaminergic systems in the rat brain. Biochemical Pharmacology. 1987; 36(5):747-55. [DOI:10.1016/00062952(87)90729-5]

[28] Rothman RB, Baumann MH, Dersch CM, Romero DV Rice KC, Carroll FI, et al. Amphetamine-type central nervous system stimulants release norepinephrine more potently than they release dopamine and serotonin. Synapse. 2001; 39(1):32-41. [DOI:10.1002/1098-2396(20010101)39:1<32::AIDSYN5 $>3.0$. CO;2-3]

[29] Sabol KE, Seiden LS. Reserpine attenuates D-amphetamine and MDMA-induced transmitter release in vivo: A consideration of dose, core temperature and dopamine synthesis. Brain Research. 1998; 806(1):69-78. [DOI:10.1016/S00068993(98)00720-3]

[30] National Institute on Drug Abuse. MDMA (Ecstasy/Molly). 2018 [Updated 2018 June]. Available from: https:/ / www. drugabuse.gov/publications/drugfacts/mdma-ecstasymolly
[31] Bolla KI, McCann UD, Ricaurte GA. Memory impairment in abstinent MDMA ("Ecstasy") users. Neurology. 1998; 51(6):1532-7. [DOI:10.1212/WNL.51.6.1532] [PMID]

[32] Kish SJ, Furukawa Y, Ang L, Vorce SP and Kalasinsky KS. Striatal serotonin is depleted in brain of a human MDMA (Ecstasy) user. Neurology. 2000; 55(2):294-6. [DOI:10.1212/ WNL.55.2.294] [PMID]

[33] Green AR, Mechan AO, Elliott JM, O'Shea E, Colado MI The pharmacology and clinical pharmacology of 3,4-methylenedioxymethamphetamine (MDMA, "ecstasy"). Pharmacological Reviews. 2003; 55(3):463-508. [DOI:10.1124/pr.55.3.3] [PMID]

[34] Rudnick G, Wall SC. The molecular mechanism of "ecstasy" (3,4-methylenedioxy-methamphetamine (MDMA)) Serotonin transporters are targets for MDMA-induced serotonin release. Proceedings of the National Academy of Sciences of the United States. 1992; 89(5):1817-21. [DOI:10.1073/ pnas.89.5.1817] [PMID] [PMCID]

[35] Thomasius R, Zapletalova P, Petersen K, Buchert R, Andresen B, Wartberg L, et al. Mood, cognition and serotonin transporter availability in current and former ecstasy (MDMA) users: The longitudinal perspective. Journal of Psychopharmacology (Oxford, England). 2006; 20(2):211-25. [DOI:10.1177/0269881106059486] [PMID]

[36] Daubert EA, Heffron DS, Mandell JW, Condron BG. Serotonergic dystrophy induced by excess serotonin. Molecular and Cellular Neuroscience. 2010; 44(3):297-306. [DOI:10.1016/j.mcn.2010.04.001] [PMID] [PMCID]

[37] American Addiction Centers. Drug Abuse and Chemical Imbalance in the Brain: Dopamine, Serotonin \& More [Internet]. 2018 [Updated 2019 June 17]. Available from: https:// americanaddictioncenters.org/health-complications-addiction/chemical-imbalance

[38] Joseph H, Stancliff S, Langrod J. Methadone Maintenance Treatment (MMT): A review of historical and clinical issues. Mount Sinai Journal of Medicine. 2000; 67(5-6):347-64. [PMID]

[39] Sun Y, Liu L, Feng J, Yue W, Lu L, Fan Y, et al. MAOA rs1137070 and heroin addiction interactively alter gray matter volume of the salience network. Scientific Reports. 2017 7:45321. [DOI:10.1038/srep45321] [PMID] [PMCID]

[40] Martinez TT, Martinez DN. A case of serotonin syndrome associated with methadone overdose. Proceedings of the Western Pharmacology Society. 2008; 51:42-4. [PMID]

[41] Rastogi R, Swarm RA, Patel TA. Case scenario: Opioid association with serotonin syndrome: Implications to the practitioners. Anesthesiology. 2011; 115(6):1291-8. [DOI:10.1097/ ALN.0b013e31823940c0] [PMID] 
This Page Intentionally Left Blank 